\title{
CONSIDERAÇÕES SOBRE A APLICABILIDADE DA CLASSIFICAÇÃO CLIMÁTICA DE THORNTHWAITE NO CONTEXTO SEMIÁRIDO DO NORDESTE BRASILEIRO: ESTUDO DE CASO DA SERRA DE BATURITÉ E SEU ENTORNO
}

\author{
SILVA NETO, José Augusto - augustosilva1994@gmail.com \\ Universidade Federal do Ceará / UFC \\ SALES, Marta Celina Linhares - mclsales@uol.com.br \\ Universidade Federal do Ceará / UFC
}

\begin{abstract}
RESUMO: A presente pesquisa pretende verificar a aplicabilidade do modelo de classificação climática proposto por Thornthwaite para a dinâmica hidroclimática do domínio semiárido do Nordeste brasileiro, usando como recorte espacial o enclave úmido conhecido como Serra de Baturité. Para a realização da classificação climática foram utilizadas as médias mensais de temperatura e pluviometria dos postos pluviométricos de Baturité, Caridade, Mulungu e Guaramiranga, no período de 1989-2018. Os resultados possibilitaram verificar a ocorrência de climas semiáridos (D) para Baturité e Caridade, sub-úmido úmido (C2) para Mulungu e úmido (B3) para Guaramiranga. Dessa forma, as variações climáticas ocasionadas pelas diferentes condições fisiográficas que se processam em função da presença da Serra de Baturité foram comprovadas de forma sistemática. No entanto, mediante a uma análise mais apurada dos resultados obtidos, foi necessária a realização de uma proposta de reorganização dos intervalos destinados à classificação dos climas secos por meio de uma subdivisão do clima semiárido (D) em três níveis de semiaridez e da adição de novos subtipos climáticos destinados a representar as variações de umidade que ocorrem no Outono e na Primavera. Ao aplicar as modificações propostas, as novas classificações proporcionaram uma leitura que melhor sintetizou a realidade climática e evidenciou de forma mais detalhada as especificidades do clima de cada ponto analisado.
\end{abstract}

PALAVRAS-CHAVe: Balanço hídrico climatológico. Enclaves úmidos. Climatologia geográfica. Clima semiárido.

\section{CONSIDERATIONS ABOUT THE APPLICABILITY OF THE THORNTHWAITE CLIMATIC CLASSIFICATION SYSTEM IN THE SEMIARID CONTEXT OF THE BRAZILIAN NORTHEAST: CASE STUDY OF THE BATURITÉ'S MOUNTAIN AND YOUR AROUND}

\begin{abstract}
This research aims to verify the applicability of the climate classification model proposed by Thornthwaite to the hydroclimatic dynamics of the semiarid domain of the Brazilian Northeast, using as a spatial cut the humid massif known as "Serra de Baturité". For the climatic classification, the monthly temperature and rainfall averages of the Baturité, Caridade, Mulungu and Guaramiranga rainfall stations were used from 1989-2018. The results made it possible to verify the occurrence of semiarid climates (D) for Baturité and Caridade, sub-humid humid (C2) for Mulungu and humid (B3) for Guaramiranga. Thus, the climatic variations caused by the different physiographic conditions that occur due to the presence of Serra de Baturité were systematically confirmed. However, through a more detailed analysis of the results obtained, it was necessary to propose a reorganization of the intervals for the classification of dry climates by subdividing the semiarid climate (D) into three levels and the addition of new climate subtypes designed to represent the humidity variations that occur in autumn and spring. Applying the proposed modifications, the new classifications provided a reading that better synthesized the climate reality and highlighted in more detail the climate specificities of each point analyzed.
\end{abstract}

KEYWORDS: Water balance. Moist massifs. Geographic climatology. Semiarid climate. 


\section{INTRODUÇÃo}

Diante da grande diversidade de climas existentes ao longo da superfície da Terra, as classificações climáticas surgem como modelos formulados com o objetivo de sintetizar as características de determinados climas por meio de um arranjo simplificado que possibilita uma organização eficiente dos dados referentes aos elementos climáticos (AYOADE, 2011).

De acordo com Ayoade (2011), o clima é a síntese da combinação singular da dinâmica geoambiental de determinada região. Portanto, o conceito de clima não pode ser reduzido a valores exatos e, por isso, a sua classificação envolve métodos de simplificação e generalização (SALES et. al., 2010). A utilização de métodos de classificação do clima, ainda que apresente limitações na árdua tarefa de representar algo tão dinâmico e complexo como o clima, possibilita compreender certos aspectos inerentes ao comportamento do regime hidroclimático de determinados ambientes.

Ao longo do tempo, vários sistemas de classificações climáticas foram elaborados por pesquisadores de diversos campos científicos nos quais o clima é um elemento central para a compreensão de determinados fenômenos. Em 1948, W. Thornthwaite publicou uma proposta para classificação racional do clima que introduziu o conceito de evapotranspiração, que representa o fluxo de retorno da água para a atmosfera mediante a evaporação no solo e da transpiração realizada pelas plantas, e de balanço hídrico entre o solo e a atmosfera (REDDY, 1983). A partir desses conceitos, foi formulado o índice de umidade efetiva (Im), para distinguir os tipos de climas secos dos climas úmidos, e os índices de aridez (Ia), de umidade (Iu), de eficiência térmica (ETP) e de efetividade térmica do verão (ETV), para definir os seus subtipos.

O método desenvolvido por Thornthwaite para estimar os valores de evapotranspiração possui diversas aplicações, sobretudo nos estudos ecológicos, agrometeorológicos e na gestão dos recursos hídricos. Porém, seu modelo não ficou isento de críticas, principalmente por não considerar os inúmeros fatores que interferem na transferência de vapor d'água para a atmosfera. Logo, a evapotranspiração calculada pelo seu método passou a servir apenas como um parâmetro climatológico comparativo (VAREJÃO-SILVA, 2001).

Além disso, o próprio sistema de classificação de Thornthwaite recebeu diversas críticas sobre sua aplicação e seus resultados, sobretudo nos trabalhos realizados em regiões tropicais áridas e semiáridas (AYOADE, 1972; KRISHNAN, 1980; REDDY, 1983; NIMER; BRANDÃO, 1985).

Portanto, a presente pesquisa pretende verificar a aplicabilidade do modelo de classificação de Thornthwaite (1948) e Thornthwaite e Matter (1955) na análise do contexto climático do domínio semiárido do Nordeste brasileiro e, a partir dos resultados, propor alterações que venham a contribuir para a obtenção de resultados mais precisos. Para isso, será utilizado como recorte espacial a serra de Baturité, localizada no Estado do Ceará, e seu entorno.

\section{MATERIAIS E MÉTODOS}

De acordo com Souza (1988), a serra de Baturité constitui um dos relevos mais expressivos diante dos compartimentos que se localizam próximos ao litoral nordestino. Se trata de um compartimento formado por um conjunto 
de litologias nas quais se destacam paragnaisses, migmatitos, anfibolitos, xistos e metacalcários que datam do Paleoproterozóico, com orientação NNE - SSE e cotas altimétricas que ultrapassam a marca de 1000 metros (BRANDÃO, 2014).

A Serra de Baturité constitui uma barreira aos ventos Alísios de Sudeste que adentram o continente carregados de umidade do Oceano Atlântico e, por isso, condicionam a ocorrência de chuvas orográficas (BÉTARD et. al., 2007). A disposição do seu relevo é um fator fundamental para a variação temporal e espacial dos elementos climáticos e é responsável pela ocorrência dos mesoclimas de altitude (AB'SABER; 1970, 1974).

As massas de ar, ao serem barradas pelo relevo, são levantadas e empurradas contra ele, então o ar contido nelas, ao ascender para altitudes mais elevadas, perde temperatura e a umidade relativa aumenta como consequência do resfriamento adiabático e, ao atingir a temperatura do ponto de orvalho, o vapor de água presente na massa de ar ascendente condensa ocasionando, entre outros fenômenos, a ocorrência de chuvas orográficas. Essa interação entre o relevo e a atmosfera resulta no beneficiamento das condições hidrológicas de suas encostas a barlavento, proporcionando a ocorrência de totais pluviométricos relativamente elevados, temperaturas mais amenas, solos mais profundos e presença de vegetação adaptada a ambientes úmidos (SOUZA; OLIVEIRA, 2006).

Em contrapartida, essa mesma relação pode desfavorecer a disponibilidade hídrica dos ambientes nas áreas localizadas a sotavento, que são geralmente caracterizadas por condições mais secas e por temperaturas mais elevadas. A queda nos totais pluviométricos que ocorre nas áreas a sotavento de um obstáculo topográfico se deve ao fato do ar sofre descompressão adiabática por já ter perdido parte ou a totalidade de sua umidade ao transpô-lo (CÂNDIDO; NUNES, 2008).

Como resultado, esses maciços proporcionam uma grande variabilidade de microclimas em seu entorno, cada um com características próprias que refletem diretamente as características geoambientais de sua área de abrangência.

Diante desse quadro, a seleção dos postos pluviométricos utilizados levou em consideração a sua localização diante da entrada de umidade atmosférica. A análise hidroclimática foi realizada a partir dos dados registrados pelos postos pluviométricos monitorados pela Fundação Cearense de Meteorologia e Recursos Hídricos (Funceme) dos municípios de Baturité, Guaramiranga, Mulungu e Caridade (Figura 1), durante o período de 1989 a 2018. 


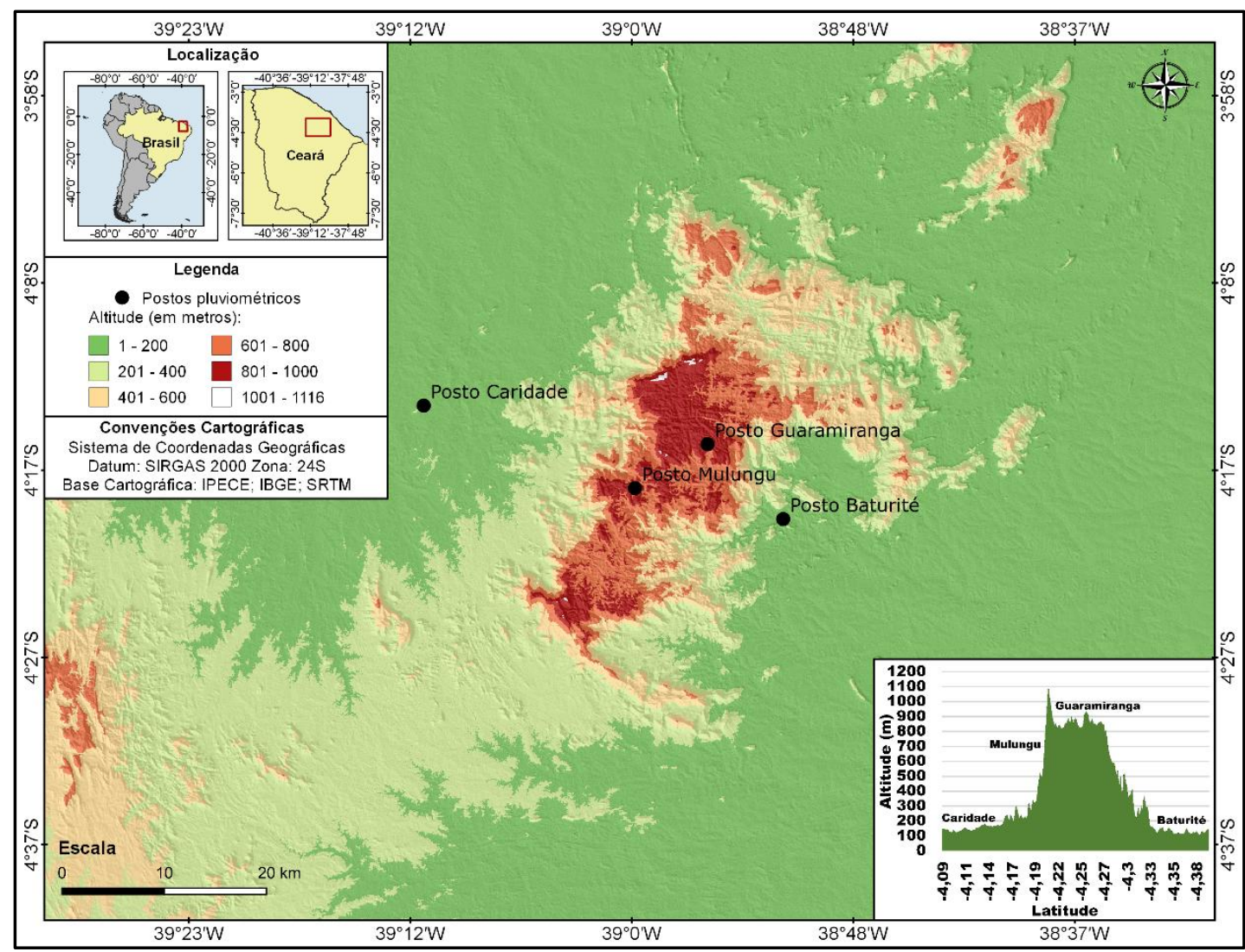

Figura 1 - Mapa hipsométrico e localização dos postos pluviométricos dos municípios de Baturité, Guaramiranga, Mulungu e Caridade. Fonte: elaborado pelo autor. Base cartográfica: Funceme (2019) e SRTM (2014).

As temperaturas médias mensais foram estimadas através do software CELINA versão 1.0, desenvolvido por Costa (2007), que utiliza os dados de latitude, longitude e altitude para estimar as temperaturas médias mensais do Estado do Ceará.

A distribuição das estações do ano foi definida segundo os períodos adotados por Rolim et. al. (2015) que os definiram de acordo com o que mostra a Tabela 1.

Tabela 1 - Intervalos das estações do ano segundo Rolim et. al. (2015).

\begin{tabular}{cc}
\hline Estação & Intervalo \\
\hline Verão & $1 / 3$ Dez. + Jan. + Fev. + 2/3 Mar. \\
Outono & $1 / 3$ Mar. + Abr. + Mai. + 2/3 Jun. \\
Inverno & $1 / 3$ Jun. + Jul. + Ago. + 2/3 Set. \\
Primavera & $1 / 3$ Set. + Out. + Nov. + 2/3 Dez. \\
\hline
\end{tabular}

Fonte: Rolim et. al. (2015).

Após a seleção e organização dos dados termopluviométricos, foi realizado o cálculo do balanço hídrico segundo o método de Thornthwaite e Matter (1955, 1957), sintetizado por Rolim et. al. (1998), e simplificado por Pereira (2005). Para a realização dos cálculos foram atribuídos $100 \mathrm{~mm}$ para a capacidade de armazenamento de água do solo (CAD). 
O balanço hídrico estimou os valores mensais e anuais de evapotranspiração potencial (ETP), de déficit (Def) e excedente (Exc) hídrico, e a partir deles foi aplicada a classificação de Thornthwaite (1948) com as alterações realizadas por Thornthwaite e Matter (1955) de acordo com seus índices climáticos. O índice de umidade efetiva (Im) determinou o tipo climático através do valor obtido pela Equação 1.

$$
\mathrm{I}_{\mathrm{m}}=\frac{100 . \mathrm{Exc}-100 . \text { Def }}{\mathrm{ETP}}
$$

Na qual:

Exc é o excedente hídrico anual;

Def é o déficit hídrico anual;

ETP é a evapotranspiração potencial anual.

A partir do resultado, seus valores foram classificados de acordo com a simbologia presente na Tabela 2.

Tabela 2 - Sistema de classificação dos valores do índice de umidade efetiva (Im) de Thornthwaite e Matter (1955).

\begin{tabular}{ccc}
\hline Símbolo & Tipo climático & $\mathbf{I}_{\mathbf{m}}(\%)$ \\
\hline$A$ & Muito úmido & $\mathrm{I}_{\mathrm{m}} \geq 100$ \\
$\mathrm{~B}_{4}$ & & $80 \leq \mathrm{I}_{\mathrm{m}}<100$ \\
$\mathrm{~B}_{3}$ & Úmido & $60 \leq \mathrm{I}_{\mathrm{m}}<80$ \\
$\mathrm{~B}_{2}$ & & $40 \leq \mathrm{I}_{\mathrm{m}}<60$ \\
$\mathrm{~B}_{1}$ & & $20 \leq \mathrm{I}_{\mathrm{m}}<40$ \\
$\mathrm{C}_{2}$ & Sub-úmido úmido & $0 \leq \mathrm{I}_{\mathrm{m}}<20$ \\
$\mathrm{C}_{1}$ & Sub-úmido seco & $-33,3 \leq \mathrm{I}_{\mathrm{m}}<0$ \\
$\mathrm{D}$ & Semiárido & $-66,7 \leq \mathrm{I}_{\mathrm{m}}<-33,3$ \\
$\mathrm{E}$ & Árido & $-100 \leq \mathrm{I}_{\mathrm{m}}<-66,7$ \\
\hline
\end{tabular}

Fonte: Thornthwaite e Matter (1955).

$O$ índice associado à definição do primeiro subtipo climático é condicionado pelo resultado do Im. Caso o Im determine um clima úmido $(A, B$ ou C2), a classificação deve ser realizada por meio do índice de aridez (Ia) expresso pela Equação 2.

$$
\mathrm{I}_{\mathrm{a}}=\left(\frac{\text { Def }}{E T P}\right) \cdot 100
$$

Na qual:

Def é o déficit hídrico anual;

ETP é a evapotranspiração potencial anual.

Caso contrário, se o Im determinar um clima seco (C1, D ou E), deve-se utilizar o índice de umidade (Iu), calculado através da Equação 3. A classificação dos resultados deve ser realizada de acordo com a Tabela 3.

$$
\mathrm{I}_{\mathrm{u}}=\left(\frac{E x C}{E T P}\right) \cdot 100
$$

Na qual:

Exc é o excedente hídrico anual;

ETP é a evapotranspiração potencial anual. 
Tabela 3 - Sistema de classificação dos valores dos índices de aridez (Ia) e de umidade (Iu).

\begin{tabular}{|c|c|c|c|}
\hline Clima & Símbolo & Descrição & Classes $\left(I_{a}\right)$ \\
\hline \multirow{5}{*}{$\begin{array}{c}\text { Úmido } \\
\left(A, B \text { e } C_{2}\right)\end{array}$} & $r$ & Déficit baixo ou inexistente & $0 \leq I_{a}<16,7$ \\
\hline & s & Déficit moderado no verão & $16,7 \leq \mathrm{Ia}<33,3$ \\
\hline & W & Déficit moderado no inverno & \multirow{3}{*}{$I_{a} \geq 33.3$} \\
\hline & $\mathrm{S}_{2}$ & Grande déficit no verão & \\
\hline & $\mathrm{w}_{2}$ & Grande déficit no inverno & \\
\hline \multirow{4}{*}{$\begin{array}{c}\text { Seco } \\
\left(C_{1}, D \text { e } E\right)\end{array}$} & $\begin{array}{c}\text { Símbolo } \\
d\end{array}$ & $\begin{array}{c}\text { Descrição } \\
\text { Excesso baixo ou inexistente }\end{array}$ & $\begin{array}{c}\text { Classes }\left(\mathbf{I}_{\mathrm{u}}\right) \\
0 \leq \mathrm{I}_{\mathrm{u}}<10\end{array}$ \\
\hline & $\mathrm{s}$ & Excesso moderado no verão & \multirow{2}{*}{$10 \leq \mathrm{I}_{\mathrm{u}}<20$} \\
\hline & w & Excesso moderado no inverno & \\
\hline & $\begin{array}{l}\mathrm{S}_{2} \\
\mathrm{~W}_{2}\end{array}$ & $\begin{array}{l}\text { Grande excesso no verão } \\
\text { Grande excesso no inverno }\end{array}$ & $I_{u} \geq 33,3$ \\
\hline
\end{tabular}

Fonte: Thornthwaite (1948).

O segundo subtipo climático refere-se à eficiência térmica do clima, que corresponde ao valor anual da evapotranspiração potencial (ETP), obtida através do balanço hídrico. Os totais de ETP anuais devem ser classificados segundo a Tabela 4.

Tabela 4 - Sistema de classificação da eficiência térmica a partir dos valores anuais de evapotranspiração potencial (ETP).

\begin{tabular}{ccc}
\hline Símbolo & Tipo Climático & Classes ETP $(\mathbf{m m})$ \\
\hline $\mathrm{A}^{\prime}$ & Megatérmico & $\mathrm{ETP} \geq 1140$ \\
$\mathrm{~B}^{\prime}{ }_{4}$ & & $1140>$ ETP $\geq 997$ \\
$\mathrm{~B}^{\prime}{ }_{3}$ & Mesotérmico & $997>$ ETP $\geq 885$ \\
$\mathrm{~B}^{\prime}{ }_{2}$ & & $885>$ ETP $\geq 712$ \\
$\mathrm{~B}_{1}^{\prime}$ & & $712>$ ETP $\geq 570$ \\
$\mathrm{C}^{\prime}{ }_{2}$ & Microtérmico & $570>$ ETP $\geq 427$ \\
$\mathrm{C}^{\prime}{ }_{1}$ & Tundra & $427>$ ETP $\geq 285$ \\
$\mathrm{D}^{\prime}$ & Gelo & $285>$ ETP $\geq 142$ \\
$\mathrm{E}^{\prime}$ & & ETP $<142$ \\
\hline
\end{tabular}

Fonte: Thornthwaite (1948).

O terceiro subtipo climático é definido pela concentração da eficiência térmica do Verão (ETV). Os valores de ETV foram obtidos através da Equação 4 e classificados de acordo como Tabela 5.

$$
E T V=\left(\frac{\Sigma E T P v}{E T P}\right) \cdot 100
$$

Na qual:

$\Sigma E P_{v}$ é o somatório dos valores de evapotranspiração potencial no período do Verão;

ETP representa o valor de evapotranspiração potencial anual. 
Tabela 5 - Classificação dos valores da efetividade térmica do verão (ETV).

\begin{tabular}{cc}
\hline Símbolo & Classes de ETV (\%) \\
\hline $\mathrm{a}^{\prime}$ & ETV $<48$ \\
$\mathrm{~b}^{\prime}{ }_{4}$ & $48 \leq \mathrm{ETV}<51,9$ \\
$\mathrm{~b}^{\prime}{ }_{3}$ & $51,9 \leq \mathrm{ETV}<56,3$ \\
$\mathrm{~b}^{\prime}{ }_{2}$ & $56,3 \leq \mathrm{ETV}<61,6$ \\
$\mathrm{~b}^{\prime}{ }_{1}$ & $61,6 \leq \mathrm{ETV}<68$ \\
$\mathrm{c}^{\prime}{ }_{2}$ & $68 \leq \mathrm{ETV}<76,3$ \\
$\mathrm{c}^{\prime}{ }_{1}$ & $76,3 \leq \mathrm{ETV}<88$ \\
$\mathrm{~d}^{\prime}$ & $88 \leq \mathrm{ETV}$ \\
\hline
\end{tabular}

Fonte: Thornthwaite (1948).

\section{RESULTADOS}

O posto pluviométrico do município de Baturité localiza-se a $133 \mathrm{~m}$ de altitude e faz parte de uma região que se encontra sobre a influência da encosta oriental da serra de Baturité. Esse quadro se refletiu em um total pluviométrico anual médio $(1002,03 \mathrm{~mm})$ consideravelmente superior às médias pluviométricas que comumente são encontradas no semiárido nordestino.

As temperaturas médias mensais são elevadas e com pouca variação ao longo do ano, com mínima de $26^{\circ} \mathrm{C}$ em abril e máxima de $27,3^{\circ} \mathrm{C}$ em janeiro e dezembro.

O balanço hídrico climatológico (Tabela 6 e Gráfico 1) demonstrou que habitualmente ocorreu deficiência hídrica na maioria dos meses, totalizando um valor anual de 752,90 mm. O excedente hídrico habitual ocorreu nos meses de Abril e Maio, compondo um total anual de 73,02 mm. Consequentemente, 0 valor do índice de umidade efetivo (Im) foi de $-40,42 \%$, indicando um clima do tipo semiárido (D), com valor do índice de umidade (Iu) de 4,34, sendo classificado como um clima de excesso hídrico pequeno ou inexistente (d).

A evapotranspiração potencial anual (ETP) foi de 1681,91 mm caracterizando um clima Megatérmico $\left(A^{\prime}\right)$. A eficiência térmica do Verão foi de $440,62 \mathrm{~mm}$, que representa $26,20 \%$ do total anual, indicando um clima do tipo $a^{\prime}$. 
Tabela 6 - Balanço hídrico do posto pluviométrico de Baturité. Legenda: P - Pluviometria $(\mathrm{mm}) ; \mathrm{T}$ - Temperatura $\left({ }^{\circ} \mathrm{C}\right)$; ETP - Evapotranspiração potencial $(\mathrm{mm})$; DEF - Deficiência hídrica $(\mathrm{mm})$; EXC - Excedente hídrico $(\mathrm{mm})$.

\begin{tabular}{cccccc}
\hline Mês & $\mathbf{T}$ & $\mathbf{P}$ & ETP & DEF & EXC \\
\hline Jan. & 27,40 & 114,20 & 160,01 & 45,80 & 0,00 \\
Fev. & 27,00 & 125,53 & 135,95 & 10,42 & 0,00 \\
Mar. & 26,40 & 198,83 & 137,06 & 0,00 & 0,00 \\
Abr. & 26,20 & 225,60 & 127,52 & 0,00 & 59,87 \\
Mai. & 26,30 & 145,58 & 132,43 & 0,00 & 13,15 \\
Jun. & 26,00 & 96,18 & 121,85 & 3,03 & 0,00 \\
Jul. & 25,80 & 49,29 & 122,13 & 32,82 & 0,00 \\
Ago. & 26,60 & 11,80 & 137,89 & 99,33 & 0,00 \\
Set. & 27,00 & 3,03 & 142,54 & 131,55 & 0,00 \\
Out. & 27,10 & 3,58 & 150,90 & 145,29 & 0,00 \\
Nov. & 27,40 & 4,92 & 153,75 & 148,37 & 0,00 \\
Dez. & 27,40 & 23,48 & 159,87 & 136,29 & 0,00 \\
\hline Total & 320,60 & 1002,03 & 1681,91 & 752,90 & 73,02 \\
\hline
\end{tabular}

Fonte: Funceme (2019). Elaborado pelos autores.

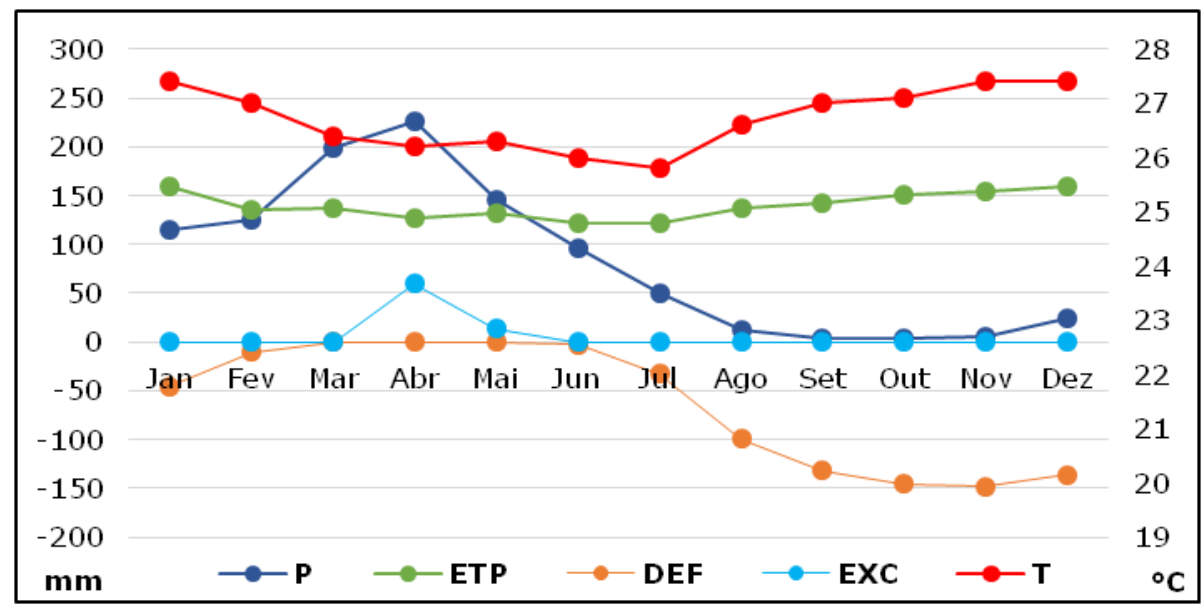

Gráfico 1 - Balanço hídrico do posto pluviométrico de Baturité. Legenda: P Pluviometria $(\mathrm{mm}) ; \mathrm{T}$ - Temperatura $\left({ }^{\circ} \mathrm{C}\right)$; ETP - Evapotranspiração potencial $(\mathrm{mm})$; DEF - Deficiência hídrica $(\mathrm{mm}) ;$ EXC - Excedente hídrico ( $\mathrm{mm})$. Fonte: Funceme (2019). Elaborado pelos autores.

O posto pluviométrico de Caridade localiza-se em uma área influenciada pela vertente ocidental da serra com cota altimétrica de $150 \mathrm{~m}$, na qual as características geoambientais se aproximam daquilo que se considera típico das regiões semiáridas do Nordeste brasileiro.

O total pluviométrico anual foi de $625,70 \mathrm{~mm}$. A menor temperatura média mensal ocorreu no mês de junho $\left(26^{\circ} \mathrm{C}\right)$ e a maior temperatura média $\left(27,4^{\circ} \mathrm{C}\right)$ nos meses de janeiro, novembro e dezembro.

De acordo com o balanço hídrico (Tabela 7 e Gráfico 2), ocorreu deficiência de água durante quase todo o ano, com exceção dos meses de março e abril em que apenas capacidade de armazenamento de água do solo foi 
suprida. Seu Im foi de $-62,13 \%$, indicando um clima semiárido (D), com um Iu foi de 0,00 , valor equivalente a um clima com excedente hídrico inexistente (d).

Foram estimados $1652,09 \mathrm{~mm}$ de ETP anual, caracterizando um clima Megatérmico $\left(A^{\prime}\right)$. A ETP ocorrida no Verão foi de $431,84 \mathrm{~mm}$, representando $26,14 \%$ do valor anual e, portanto, foi classificado como um clima do tipo a'.

Tabela 7 - Balanço hídrico do posto pluviométrico de Caridade. Legenda: P Pluviometria $(\mathrm{mm}) ; \mathrm{T}$ - Temperatura $\left({ }^{\circ} \mathrm{C}\right) ;$ ETP - Evapotranspiração potencial $(\mathrm{mm})$; DEF - Deficiência hídrica $(\mathrm{mm})$; EXC - Excedente hídrico $(\mathrm{mm})$.

\begin{tabular}{cccccc}
\hline Mês & $\mathbf{T}$ & $\mathbf{P}$ & $\mathbf{E T P}$ & DEF & EXC \\
\hline Jan. & 27,30 & 105,30 & 157,88 & 52,58 & 0,00 \\
Fev. & 26,80 & 91,52 & 132,36 & 40,84 & 0,00 \\
Mar. & 26,20 & 153,06 & 133,53 & 0,00 & 0,00 \\
Abr. & 26,00 & 150,26 & 124,29 & 0,00 & 0,00 \\
Mai. & 26,10 & 74,89 & 129,09 & 35,16 & 0,00 \\
Jun. & 25,90 & 23,17 & 120,56 & 80,92 & 0,00 \\
Jul. & 25,70 & 13,18 & 120,88 & 101,10 & 0,00 \\
Ago. & 26,50 & 3,61 & 136,31 & 130,20 & 0,00 \\
Set. & 26,90 & 0,73 & 140,80 & 139,39 & 0,00 \\
Out. & 27,00 & 0,63 & 149,00 & 148,20 & 0,00 \\
Nov. & 27,20 & 0,42 & 149,65 & 149,19 & 0,00 \\
Dez. & 27,30 & 8,93 & 157,74 & 148,81 & 0,00 \\
\hline Total & 318,90 & 625,71 & 1652,09 & 1026,38 & 0,00 \\
\hline
\end{tabular}

Fonte: Funceme (2019). Elaborado pelos autores.

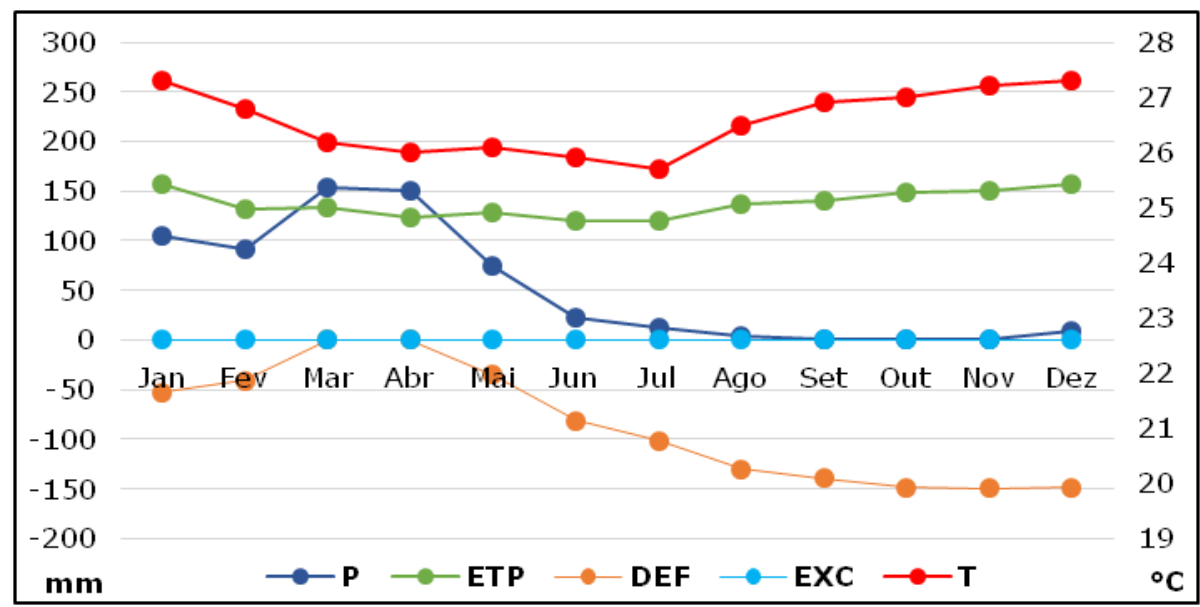

Gráfico 2 - Balanço hídrico do posto pluviométrico de Caridade. Legenda: P Pluviometria $(\mathrm{mm}) ; \mathrm{T}$ - Temperatura $\left({ }^{\circ} \mathrm{C}\right)$; ETP - Evapotranspiração potencial $(\mathrm{mm})$; DEF - Deficiência hídrica $(\mathrm{mm}) ;$ EXC - Excedente hídrico $(\mathrm{mm})$. Fonte: Funceme (2019). Elaborado pelos autores.

O posto pluviométrico de Mulungu situa-se sobre a vertente ocidental do maciço de Baturité, a cerca de $784 \mathrm{~m}$ de altitude. O posto de Mulungu $(1018,78$ $\mathrm{mm}$ ) apresentou uma pluviometria anual média bastante próxima do valor registrado em Baturité $(1002,03 \mathrm{~mm})$ que, apesar de localizar-se no "sopé" da 
serra, encontra-se numa posição mais favorável com relação à entrada de umidade no continente.

Em contrapartida, a cota altimétrica elevada em que o posto de Mulungu se encontra fez com que as temperaturas médias mensais apresentassem um decréscimo de cerca de $5^{\circ} \mathrm{C}$ com relação as temperaturas médias das áreas do entorno da serra. A mínima média ocorreu no mês de julho $\left(20,3^{\circ} \mathrm{C}\right)$ e a máxima média no mês de janeiro $\left(22^{\circ} \mathrm{C}\right)$.

O balanço hídrico (Tabela 8 e Gráfico 3) apontou um excedente anual de $297,38 \mathrm{~mm}$. e deficiência de 277,41 mm/ano. O Im para Mulungu foi de 1,98\%, classificando-o com um clima sub-úmido úmido (C2), com Ia de 27,78, que representa um déficit moderado durante o inverno $(w)$.

As temperaturas mais amenas refletiram diretamente nos valores de evapotranspiração potencial. O total anual foi de $998,96 \mathrm{~mm}$, originando um clima quarto mesotérmico ( $\left.B^{\prime} 4\right)$. Durante o verão a evapotranspiração potencial foi de 265, $04 \mathrm{~mm}$, que representa $26,53 \%$ do valor anual, indicando um clima do tipo $a^{\prime}$.

Tabela 8 - Balanço hídrico do posto pluviométrico de Mulungu. Legenda: $P$ Pluviometria $(\mathrm{mm}) ; \mathrm{T}$ - Temperatura $\left({ }^{\circ} \mathrm{C}\right)$; ETP - Evapotranspiração potencial $(\mathrm{mm})$; DEF - Deficiência hídrica (mm); EXC - Excedente hídrico (mm).

\begin{tabular}{cccccc}
\hline Mês & T & P & ETP & DEF & EXC \\
\hline Jan. & 22,30 & 117,08 & 94,81 & 0,00 & 0,00 \\
Fev. & 21,90 & 110,05 & 81,56 & 0,00 & 0,00 \\
Mar. & 21,60 & 195,28 & 86,65 & 0,00 & 61,73 \\
Abr. & 21,30 & 199,11 & 80,25 & 0,00 & 118,86 \\
Mai. & 21,30 & 157,41 & 82,14 & 0,00 & 75,27 \\
Jun. & 20,70 & 115,22 & 73,70 & 0,00 & 41,52 \\
Jul. & 20,30 & 62,95 & 72,58 & 0,45 & 0,00 \\
Ago. & 21,00 & 16,90 & 79,16 & 20,17 & 0,00 \\
Set. & 21,50 & 6,20 & 81,82 & 49,77 & 0,00 \\
Out. & 21,60 & 3,73 & 86,36 & 69,76 & 0,00 \\
Nov. & 21,90 & 8,18 & 87,22 & 73,58 & 0,00 \\
Dez. & 22,10 & 26,67 & 92,70 & 63,83 & 0,00 \\
\hline Total & 257,50 & 1018,78 & 998,96 & 277,55 & 297,38 \\
\hline
\end{tabular}

Fonte: Funceme (2019). Elaborado pelo autor. 


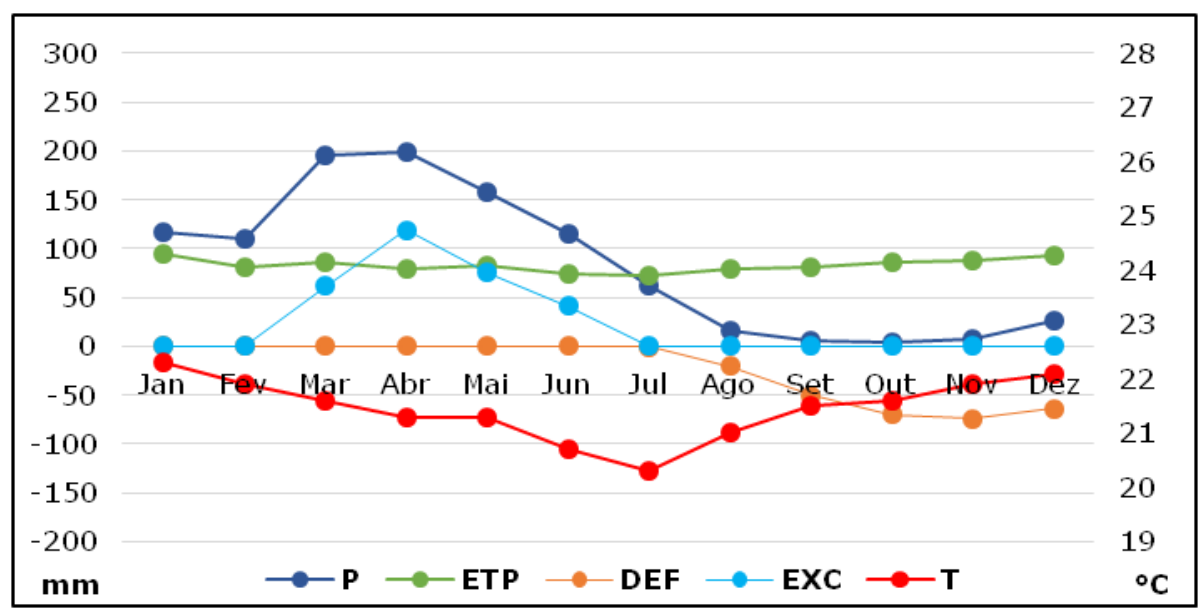

Gráfico 3 - Balanço hídrico do posto pluviométrico de Mulungu. Legenda: P Pluviometria $(\mathrm{mm}) ; \mathrm{T}$ - Temperatura $\left({ }^{\circ} \mathrm{C}\right)$; ETP - Evapotranspiração potencial $(\mathrm{mm})$; DEF - Deficiência hídrica $(\mathrm{mm})$; EXC - Excedente hídrico $(\mathrm{mm})$. Fonte: Funceme (2019). Elaborado pelos autores.

O posto pluviométrico de Guaramiranga está situado sobre a vertente oriental da serra de Baturité, na cota altimétrica de $874 \mathrm{~m}$. A altitude elevada, somada com grande exposição à umidade advinda do Atlântico, resultou em um total pluviométrico médio anual bastante expressivo (1521,61 mm), e em temperaturas médias mensais consideravelmente mais baixas do que os demais pontos analisados, com mínima de $19,4^{\circ} \mathrm{C}$ em julho e máxima de $21,5^{\circ} \mathrm{C}$ em janeiro.

Como mostra o balanço hídrico (Tabela 9 e Gráfico 4), o excedente hídrico prevaleceu na maioria dos meses e totalizou de $724,61 \mathrm{~mm} / \mathrm{ano}$. A deficiência hídrica ocorreu no período de agosto a dezembro totalizando de $146,94 \mathrm{~mm} /$ ano. O Im foi de $61,20 \%$, apresentando um clima úmido (B3), com Ia de 15,57, sendo assim atribuído um clima com pequeno déficit ( $r$ ).

A taxa anual de evapotranspiração potencial foi de $943,93 \mathrm{~mm}$, valor classificado como um clima terceiro mesotérmico ( $\left.B^{\prime} 3\right)$. O período do Verão foi responsável por $251,45 \mathrm{~mm}$ de evapotranspiração potencial, o que representa $26,64 \%$ da eficiência térmica anual e, portanto, recebeu a classificação de clima do tipo a'. 
Tabela 9 - Balanço hídrico do posto pluviométrico de Guaramiranga. Legenda: P Pluviometria $(\mathrm{mm}) ; \mathrm{T}$ - Temperatura $\left({ }^{\circ} \mathrm{C}\right) ; \mathrm{ETP}$ - Evapotranspiração potencial $(\mathrm{mm})$; DEF - Deficiência hídrica $(\mathrm{mm})$; EXC - Excedente hídrico $(\mathrm{mm})$.

\begin{tabular}{cccccc}
\hline Mês & T & P & ETP & DEF & EXC \\
\hline Jan. & 21,50 & 172,85 & 89,36 & 0,00 & 0,00 \\
Fev. & 21,20 & 156,99 & 77,79 & 0,00 & 71,97 \\
Mar. & 20,90 & 264,40 & 82,74 & 0,00 & 181,66 \\
Abr. & 20,50 & 287,46 & 75,87 & 0,00 & 211,59 \\
Mai. & 20,50 & 202,63 & 77,66 & 0,00 & 124,96 \\
Jun. & 19,90 & 161,16 & 69,81 & 0,00 & 91,35 \\
Jul. & 19,40 & 111,10 & 68,03 & 0,00 & 43,07 \\
Ago. & 20,20 & 30,78 & 74,91 & 8,45 & 0,00 \\
Set. & 20,60 & 18,50 & 76,47 & 29,67 & 0,00 \\
Out. & 20,80 & 24,84 & 81,57 & 41,13 & 0,00 \\
Nov. & 21,10 & 29,07 & 82,31 & 44,80 & 0,00 \\
Dez. & 21,30 & 61,83 & 87,42 & 22,88 & 0,00 \\
\hline Total & 247,90 & 1521,61 & 943,93 & 146,94 & 724,61 \\
\hline
\end{tabular}

Fonte: Funceme (2019). Elaborado pelos autores.

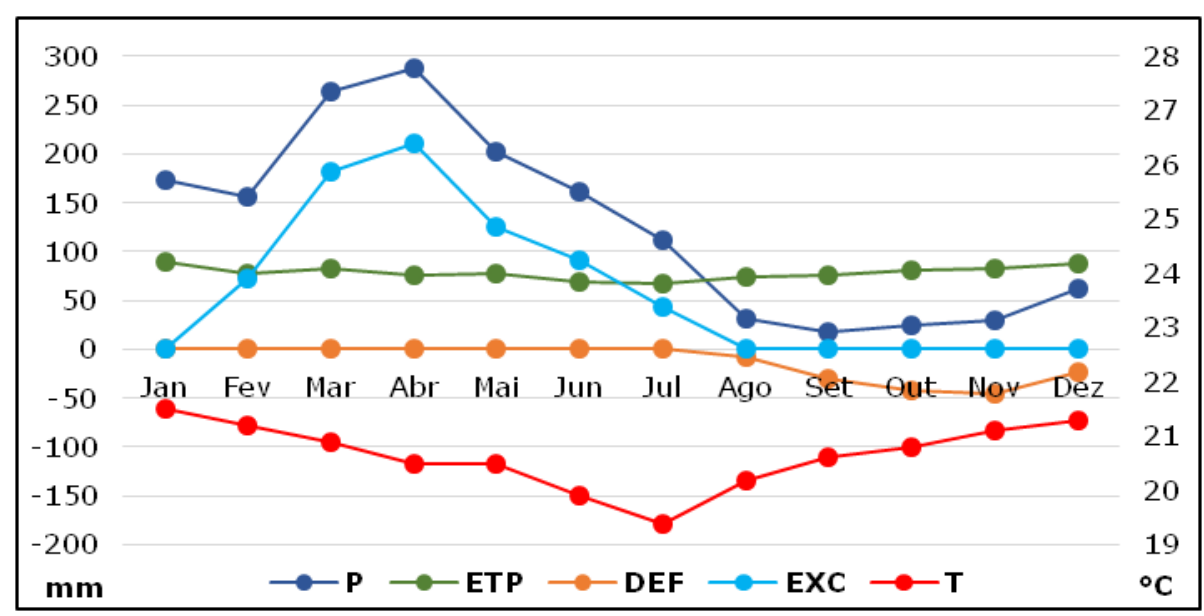

Gráfico 3 - Balanço hídrico do posto pluviométrico de Guaramiranga. Legenda: P Pluviometria $(\mathrm{mm}) ; \mathrm{T}$ - Temperatura $\left({ }^{\circ} \mathrm{C}\right)$; ETP - Evapotranspiração potencial $(\mathrm{mm})$; DEF - Deficiência hídrica (mm); EXC - Excedente hídrico ( $\mathrm{mm})$. Fonte: Funceme (2019). Elaborado pelos autores.

\section{DISCUSSÃO}

\subsection{ANÁLISE E PROPOSTA DE MODIFICAÇÃO NA CLASSIFICAÇÃO PARA $O$ ÍNDICE DE UMIDADE EFETIVA $\left(I_{m}\right)$}

Na proposta inicial de classificação climática de Thornthwaite, publicada em 1948, o índice de umidade efetiva $\left(\mathrm{I}_{\mathrm{m}}\right.$ ) considerava que o excedente hídrico tinha um peso maior do que a deficiência hídrica. Portanto, eram atribuídos coeficientes com valores distintos a cada um de seus índices, de tal forma que o índice de aridez $\left(\mathrm{I}_{\mathrm{a}}\right.$ ) era obtido através do resultado da divisão entre a 
deficiência hídrica anual (DEF) e a evapotranspiração potencial anual (ETP) multiplicada por 60 (Equação 5). Enquanto o índice de umidade $\left(\mathrm{I}_{\mathrm{u}}\right.$ ) era obtido através do resultado da divisão entre o excedente hídrico anual (EXC) e a evapotranspiração potencial anual (ETP) multiplicada por 100, conforme mostra a Equação 3.

$$
\mathrm{I}_{\mathrm{a}}=\left(\frac{D E F}{E T P}\right) \cdot 60(5)
$$

Posteriormente, em 1955, Thornthwaite e Matter publicaram uma revisão do sistema de classificação climática em que o índice de aridez passou a ser multiplicado por um coeficiente de valor 100 (como mostra a Equação 2), de forma semelhante ao índice de umidade. Essa mudança alterou o valor mínimo que $o$ índice de umidade efetiva poderia atingir, passando de -60 para -100 , afetando apenas os climas secos, que tiveram seus intervalos ampliados para se adaptar aos novos valores e, assim, os climas sub-úmido seco (C1), semiárido (D) e árido (E) passaram a abranger os intervalos mais extensos da nova classificação climática.

Como consequência, ao aplicar o sistema de Thornthwaite e Matter (1955), a classificação a partir do índice de umidade efetiva (Im) mostrou um grau de generalização elevado para a determinação dos climas secos, que pode ser observada a partir da tipologia atribuída aos postos pluviométricos de Baturité e Caridade, ambos classificados como clima semiárido (D).

Conforme mostrado pelo balanço hídrico climatológico, tanto o posto de Baturité quanto o posto de Caridade apresentam uma alta demanda térmica que justificou a ocorrência de climas megatérmicos $\left(A^{\prime}\right)$. No entanto, apesar de apresentarem a mesma tipologia climática e eficiências térmicas semelhantes, a pluviometria anual registrada pelo posto de Baturité é consideravelmente mais elevada, o que proporciona condições hidroclimáticas mais favoráveis se comparadas ao posto de Caridade.

Colaborando para a compreensão das características do semiárido brasileiro, Conti (2005) afirma que esse domínio climático está longe de ser homogêneo e apresenta características distintas conforme as variações dos fatores geoecológicos locais. Segundo o autor, o Nordeste brasileiro constitui um mosaico variado de paisagens em que o relevo regional possui importante papel na determinação das diferenças ambientais, sobretudo aquelas que são determinadas pela relação de barlavento e sotavento.

Sendo assim, é importante ainda salientar que o posto de Baturité e o posto de Caridade se localizam em setores bastante distintos da serra de Baturité e, consequentemente, essas localidades apresentam características geoambientais e bioclimáticas que refletem essa configuração. Nas áreas sertanejas localizadas no setor a barlavento, na porção oriental do maciço (Figura 2), fica evidenciada a presença de relevos com topografias planas e moderadamente dissecadas com caatingas hipexerófitas, o que se deve à influência edafo-climática que apresenta condições menos severas em termos de aridez, se comparado com os setores sertanejos a sotavento (Figura 3), localizados no setor ocidental do maciço (BASTOS et. al., 2017). 


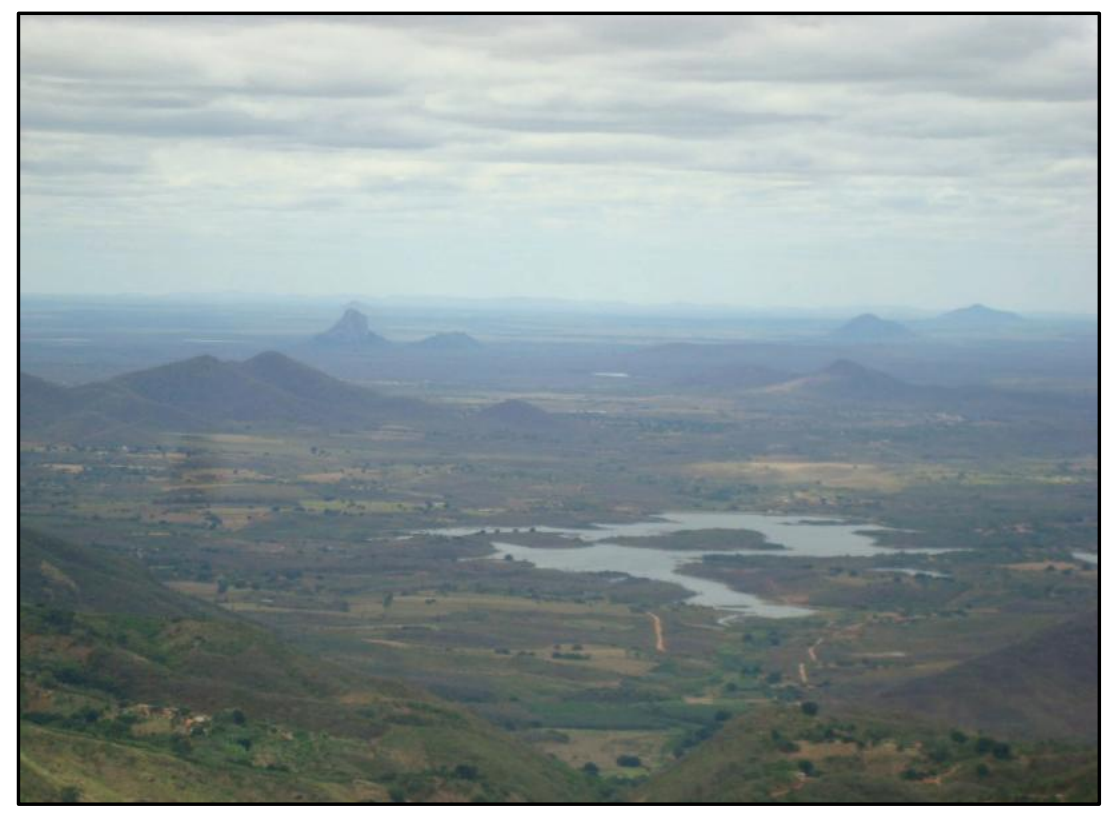

Figura 2 - Vista para superfície de aplainamento sertaneja voltada para o setor oriental (barlavento) da serra de Baturité. Fonte: extraído de Bastos et. al. (2017).

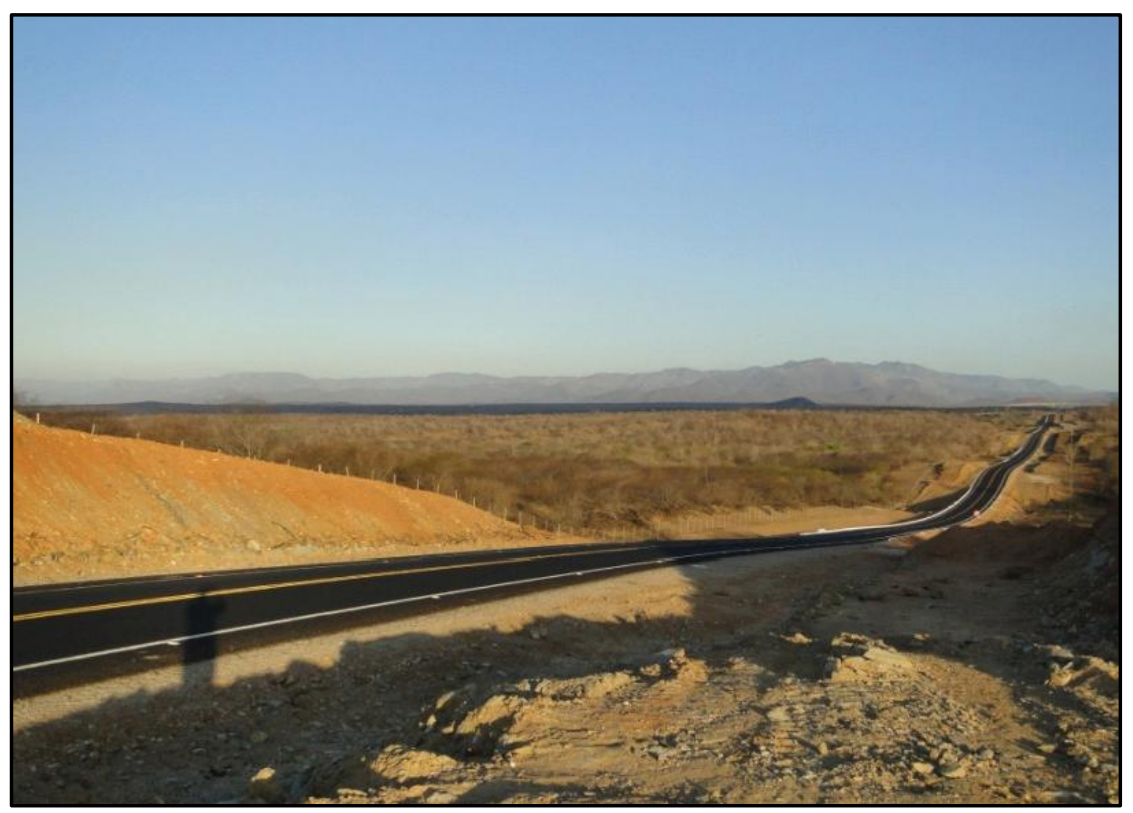

Figura 3 - Superfície sertaneja localizada no setor ocidental (sotavento) da serra de Baturité (ao fundo). Fonte: extraído de Bastos et. al. (2017).

Assim, buscando contemplar as variações dos níveis de semiaridez de forma mais precisa, o presente artigo propõe uma modificação nos intervalos da classificação de Thornthwaite e Matter (1955), em que os climas secos passam a ocupar intervalos com extensões semelhantes àquelas designadas aos climas úmidos. Dessa forma, o clima Sub-úmido seco $\left(C_{1}\right)$ passa a ser atribuído para o intervalo de $-20 \% \leq \mathrm{I}_{\mathrm{m}}<0 \%$, e o clima Semiárido (D) passa a ser subdividido em 3 classes: Semiárido $\left(D_{3}\right)$ para $-40 \% \leq I_{m}<-20 \%$; Semiárido $\left(D_{2}\right)$ para $60 \% \leq \mathrm{I}_{\mathrm{m}}<-40 \%$; e Semiárido $\left(\mathrm{D}_{1}\right)$ para $-80 \% \leq \mathrm{I}_{\mathrm{m}}<-60 \%$. O clima Árido $(\mathrm{E})$, 
por sua vez, deve ser considerado quando $-100 \% \leq \mathrm{I}_{\mathrm{m}}<-80 \%$, conforme a Tabela 10.

Tabela 10 - Proposta de modificação no sistema de classificação para o índice de umidade efetiva (Im) de Thornthwaite e Matter (1955).

\begin{tabular}{ccc}
\hline Símbolo & Tipo climático & $\mathbf{I}_{\mathbf{m}} \mathbf{( \% )}$ \\
\hline$A$ & Muito úmido & $\mathrm{I}_{\mathrm{m}} \geq 100$ \\
$\mathrm{~B}_{4}$ & & $80 \leq \mathrm{I}_{\mathrm{m}}<100$ \\
$\mathrm{~B}_{3}$ & Úmido & $60 \leq \mathrm{I}_{\mathrm{m}}<80$ \\
$\mathrm{~B}_{2}$ & & $40 \leq \mathrm{I}_{\mathrm{m}}<60$ \\
$\mathrm{~B}_{1}$ & & $20 \leq \mathrm{I}_{\mathrm{m}}<40$ \\
$\mathrm{C}_{2}$ & Sub-úmido úmido & $0 \leq \mathrm{I}_{\mathrm{m}}<20$ \\
$\mathrm{C}_{1}$ & Sub-úmido seco & $-20 \leq \mathrm{I}_{\mathrm{m}}<0$ \\
$\mathrm{D}_{3}$ & & $-40 \leq \mathrm{I}_{\mathrm{m}}<-20$ \\
$\mathrm{D}_{2}$ & Semiárido & $-60 \leq \mathrm{I}_{\mathrm{m}}<-40$ \\
$\mathrm{D}_{1}$ & & $-80 \leq \mathrm{I}_{\mathrm{m}}<-60$ \\
$\mathrm{E}$ & Árido & $-100 \leq \mathrm{I}_{\mathrm{m}}<-80$ \\
\hline
\end{tabular}

Fonte: Elaborado pelos autores.

Seguindo a proposta acima, se torna possível diferenciar os graus de semiaridez que os postos de Baturité $\left(I_{m}-40,42 \%\right)$ e Caridade $\left(I_{m}-62,13 \%\right)$ apresentaram, sendo classificados, respectivamente, como semiárido $\left(D_{2}\right)$ e semiárido $\left(D_{1}\right)$. Enquanto os postos de Mulungu $\left(I_{m} 1,98 \%\right)$ e Guaramiranga $\left(I_{m}\right.$ $61,20 \%)$, por terem apresentado climas úmidos, não tiveram alterações nas classificações atribuídas pelo método de Thornthwaite e Matter (1955)

\subsection{ANÁLISE E PROPOSTA DE MODIFICAÇÃO NA CLASSIFICAÇÃO PARA OS ÍNDICES DE ARIDEZ $\left(I_{a}\right)$ E DE UMIDADE $\left(I_{u}\right)$}

Os resultados obtidos através da classificação dos índices de aridez (Ia) e de umidade (Iu) mostraram-se inconsistentes, já que o sistema de classificação utilizado contempla apenas as variações de umidade das estações do verão (s, s2) e inverno (w, w2). Essas estações são utilizadas como parâmetro de determinação da variação sazonal de umidade pois a elaboração do referido sistema de classificação teve como laboratório o território dos Estados Unidos da América, que se trata de um país de clima temperado em que, via de regra, as estações do ano apresentam significativas variações de temperatura, com verões quentes e secos, enquanto os invernos, são frios e úmidos (THORNTHWAITE, 1948).

Nimer (1989), em seu clássico trabalho sobre as características climáticas do Nordeste brasileiro, verificou que há uma diferenciação na sazonalidade dos períodos secos ao longo dessa região. Esse autor destacou que os períodos com escassez de chuvas podem ocorrer nos intervalos de Primavera-Verão, Inverno-Primavera, Inverno-Primavera-Verão e OutonoInverno-Primavera. Sendo assim verificada uma distribuição heterogênea na dinâmica hidroclimática regional.

No caso do semiárido do norte do Nordeste, devido a pequena variação mensal e sazonal de temperatura, a precipitação apresenta-se como o fator determinante na variação de umidade. Nesse sentido, destaca-se a atuação da Zona de Convergência Intertropical (ZCIT) como o principal sistema atmosférico 
produtor de chuvas, sobretudo nos setores norte e noroeste da região. Sua formação é associada à confluência dos alísios de NE e SE, atuando entre os meses de fevereiro a maio. Seu deslocamento para a região ocorre no Verão, atingindo sua posição mais meridional no Outono (FERREIRA; MELLO, 2005; ZANELLA, 2014).

Zanella (2014) observa ainda a atuação de outros sistemas atmosféricos como os Vórtices Ciclônicos de Altos Níveis (VCAN), as Linhas de Instabilidades (LI), Ondas de Leste (OL) e os Complexos Convectivos de Mesoescala (CCM), que contribuem em menor quantidade para a composição do total pluviométrico anual, como mostra a Tabela 11.

Tabela 11 - Distribuição sazonal dos sistemas atmosféricos produtores de chuvas no Nordeste brasileiro. Legenda: VCAN (Vórtices Ciclônicos de Altos Níveis); LI (Linhas de Estabilidade); ZCIT (Zona de Convergência Intertropical); OL (Ondas de Leste).

\begin{tabular}{ccc}
\hline Mês & Estação (dia) & Sistema Atuante \\
\hline Jan. & Verão & VCAN e LI \\
Fev. & Verão (até dia 20) & ZCIT, VCAN e LI \\
Mar. & Outono (a partir do dia 21) & ZCIT e LI \\
Abr. & Outono & ZCIT \\
Mai. & Outono (até dia 20) & ZCIT \\
Jun. & Inverno (a partir do dia 21) & OL \\
Jul. & Inverno & OL \\
Ago. & Inverno (até dia 20) & OL \\
Set. & Primavera (a partir do dia 21) & - \\
Out. & Primavera & - \\
Nov. & Primavera (até dia 20) & - \\
Dez. & Verão (a partir do dia 21) & LI \\
\hline
\end{tabular}

Fonte: Ferreira e Mello (2005) e Zanella (2014). Elaborado pelos autores.

De acordo com os dados pluviométricos analisados, a sazonalidade das chuvas, regida pela dinâmica atmosférica, ocasionou uma concentração das precipitações nos meses de Verão e Outono, enquanto os meses de Inverno e Primavera, pela a ausência de uma influência significativa de sistemas atmosféricos produtores de chuvas, foram caracterizados por um período de estiagem prolongada. Consequentemente, os maiores déficits hídricos ocorreram na Primavera e os excedentes mais significativos ocorreram no Outono (Tabela 12).

Tabela 12 - Balanço hídrico sazonal (em $\mathrm{mm}$ ) dos postos pluviométricos de Baturité, Mulungu, Guaramiranga e Caridade.

\begin{tabular}{ccccc}
\hline Estação & Baturité & Mulungu & Guaramiranga & Caridade \\
\hline Verão & $-101,65$ & 19,88 & 185,45 & $-143,01$ \\
Outono & 71,00 & 242,39 & 458,01 & $-89,10$ \\
Inverno & $-220,86$ & $-39,96$ & 45,29 & $-351,20$ \\
Primavera & $-428,37$ & $-202,48$ & $-111,08$ & $-443,06$ \\
\hline Total & $-679,88$ & 19,82 & 577,68 & $-1026,38$ \\
\hline
\end{tabular}

Fonte: Funceme (2019). Elaborado pelos autores. 
Desse modo, é proposto a adição de quatro tipos climáticos, sendo dois referentes às variações de umidade para o outono $\left(a, a_{2}\right)$, e dois para a primavera $\left(p, p_{2}\right)$. É oportuno também aderir às proposições de Nimer e Brandão (1985) que passam a distinguir os climas com valores inexistentes de aridez $\left(I_{a}=0\right)$ e umidade $\left(I_{u}=0\right)$, daqueles com baixos valores de aridez $(0<$ $\left.I_{a}<16,7\right)$ e de umidade $\left(0<I_{u}<10,0\right)$. Para aqueles com valores de $I_{a}$ e $I_{u}$ iguais a zero, os referidos autores designaram os símbolos $r$ e $d$, respectivamente. Enquanto os que apresentam um pequeno valor, mas diferente de zero, foram denominados de $r_{2}$ e $d_{2}$, respectivamente.

A Tabela 13 apresenta o sistema de classificação de Thornthwaite (1948) com as alterações propostas.

Tabela 13 - Proposta de modificação na classificação da variação sazonal de umidade de Thornthwaite (1948).

\begin{tabular}{|c|c|c|c|}
\hline Clima & Símbolo & Descrição & Classes $\left(I_{a}, I_{u}\right)$ \\
\hline \multirow{10}{*}{$\begin{array}{c}\text { Climas } \\
\text { Úmidos } \\
\left(\mathrm{A}, \mathrm{B} \text { e } \mathrm{C}_{2}\right)\end{array}$} & $r$ & Déficit inexistente & $I_{a}=0$ \\
\hline & $r_{2}$ & Déficit baixo & $0<\mathrm{I}_{a}<16,7$ \\
\hline & $\mathrm{s}$ & Déficit moderado no verão & \multirow{3}{*}{$16,7 \leq \mathrm{I}_{\mathrm{a}}<33,3$} \\
\hline & $a$ & Déficit moderado no outono & \\
\hline & w & Déficit moderado no inverno & \\
\hline & $\mathrm{p}$ & Déficit moderado na primavera & \multirow{5}{*}{$I_{a} \geq 33.3$} \\
\hline & $\mathrm{S}_{2}$ & Grande déficit no verão & \\
\hline & $a_{2}$ & Grande déficit no outono & \\
\hline & $w_{2}$ & Grande déficit no inverno & \\
\hline & $p_{2}$ & Grande déficit na primavera & \\
\hline \multirow{10}{*}{$\begin{array}{l}\text { Climas Secos } \\
\left(C_{1}, D \text { e } E\right)\end{array}$} & $\mathrm{d}$ & Excesso inexistente & $\mathrm{I}_{\mathrm{u}}=0$ \\
\hline & $d_{2}$ & Excesso baixo & $0<\mathrm{I}_{\mathrm{u}}<10,0$ \\
\hline & s & Excesso moderado no verão & \multirow{4}{*}{$10 \leq \mathrm{I}_{\mathrm{u}}<20,0$} \\
\hline & a & Excesso moderado no outono & \\
\hline & w & Excesso moderado no inverno & \\
\hline & $\mathrm{p}$ & Excesso moderado na primavera & \\
\hline & $\mathrm{S}_{2}$ & Grande excesso no verão & \multirow{4}{*}{$\mathrm{I}_{\mathrm{u}} \geq 20,0$} \\
\hline & $a_{2}$ & Grande excesso no outono & \\
\hline & $w_{2}$ & Grande excesso no inverno & \\
\hline & $\mathrm{p}_{2}$ & Grande excesso na primavera & \\
\hline
\end{tabular}

Fonte: Thornthwaite (1948), Nimer e Brandão (1985). Com alterações dos autores.

Segundo o sistema de classificação modificado, os valores do Iu indicaram para Baturité $(4,34)$ um clima do tipo d2, pois há a ocorrência de um pequeno excedente, e para Caridade $(0,00)$ um clima d, já que não há excedente hídrico. De acordo com os valores do Ia, Mulungu $(27,78)$ apresentou um clima do tipo $p$, que indica um déficit moderado na primavera, e para Guaramiranga $(15,57)$ foi atribuído um clima do tipo $\mathrm{r} 2$, indicando um pequeno valor de déficit hídrico anual. 


\subsection{ANÁLISE SOBRE A CLASSIFICAÇÃO DA EFICIÊNCIA TÉRMICA (ETP) E DA CONCENTRAÇÃO DA EFICIÊNCIA TÉRMICA DO VERÃO (ETV)}

A classificação da eficiência térmica a partir das taxas anuais de evapotranspiração potencial (ETP), serviram adequadamente como um parâmetro climático comparativo. Os postos de Baturité e Caridade, localizados no entorno da serra de Baturité apresentaram climas megatérmicos $\left(A^{\prime}\right)$, enquanto Mulungu e Guaramiranga, situados sobre a serra, foram classificados com climas mesotérmicos B'3 e B'4, respectivamente.

As variações de eficiência térmica entre os postos analisados foram causadas, sobretudo, pela influência que as cotas altimétricas exerceram nos valores das temperaturas médias mensais, evidenciando uma forte interação do controle geográfico sobre o clima por meio do beneficiamento termopluviométrico das regiões em que se localizam sobre os enclaves úmidos (CONTI, 2005; SALES et. al., 2010).

Os valores da eficiência térmica do verão (ETV) corresponderam aquilo que foi verificado por Thornthwaite (1948). Para esse autor, como as regiões equatoriais apresentam uma variação sazonal de temperatura muito pequena, a evapotranspiração nos três meses de verão costuma representar apenas cerca de $25 \%$ do valor anual da ETP. À medida em que os valores de latitude se distanciam em direção aos polos esse índice pode atingir até $100 \%$ do total anual, como é o caso das regiões polares. Colaborando com a teoria de Thornthwaite, todos os postos analisados apresentaram o índice de ETV < $48,0 \%$ e, consequentemente, foram classificados com o clima a'.

\section{CONCLUSÃO E CONSIDERAÇÕES FINAIS}

A aplicação do método de classificação de Thornthwaite e Matter (1955) definiu de forma sistemática a ocorrência de climas semiáridos para Baturité $\left(D_{d} A^{\prime} a^{\prime}\right)$ e Caridade (DdA'a'), sub-úmido úmido para Mulungu $\left(C_{2} w^{\prime} 4 a^{\prime}\right)$, e úmido para Guaramiranga $\left(B_{3} r B^{\prime} 3 a^{\prime}\right)$, verificando assim as variações climáticas ocasionadas pelas diferentes condições fisiográficas que se processam em função da presença da Serra de Baturité e pela exposição diferenciada de suas vertentes à dinâmica atmosférica regional.

No entanto, a classificação dos valores referentes a climas secos apresentou resultados excessivamente generalizadores e, portanto, foi realizado uma proposta de reorganização dos intervalos de classificação por meio da subdivisão do clima semiárido (D) em três diferentes níveis de semiaridez. A partir de então, foram obtidos resultados satisfatórios na diferenciação dos níveis de aridez apresentados pelos postos pluviométricos de Baturité e Caridade.

A proposta de classificação da variação sazonal de umidade apresentou diferenças consideráveis com relação à dinâmica climática da área de estudo. Assim, foi necessária a adição dos climas: a e $a_{2}$, para representar as variações significativas de umidade do Outono; os climas $\mathrm{p}$ e $\mathrm{p}_{2}$, para representar as variações significativas de umidade de Primavera; e os climas $r$ e $r_{2}$, propostos por Nimer e Brandão (1985), com o objetivo de diferenciar os tipos climáticos em que não ocorrem déficit/excedente hídrico daqueles em que ocorrem em pequena quantidade. 
Ao aplicar as modificações propostas, os dados do posto pluviométrico de Baturité passaram a ser classificados como um clima do tipo $D_{2} d_{2} A^{\prime} a^{\prime}$, e os dados do posto de Caridade foram classificados como $D_{1} d A^{\prime} a^{\prime}$. Para os registros do posto de Mulungu passou a ser atribuído um clima $\mathrm{C}_{2} \mathrm{pB}^{\prime} 4 \mathrm{a}^{\prime}$, e para Guaramiranga, um clima do tipo $\mathrm{B}_{3} \mathrm{r}_{2} \mathrm{~B}^{\prime} 3 \mathrm{a}^{\prime}$. Dessa forma, o objetivo da pesquisa foi alcançado, pois as alterações propostas representaram melhorias no sistema de classificação original e proporcionaram uma leitura que melhor sintetizou a realidade climática, evidenciando de forma mais detalhada as especificidades do clima de cada ponto analisado.

Por fim, foi elaborada a Planilha de Classificação Racional do Clima (PCRC) desenvolvida no programa Microsoft Excel. A partir da inserção dos dados de latitude, capacidade de armazenamento de água do solo, temperatura e pluviometria mensal, a PCRC realiza automaticamente a classificação climática dos dados de acordo com as modificações propostas nos modelos de classificação presente artigo. Espera-se assim que, a partir de então a PCRC, possa ser utilizada, testada e que futuramente sejam realizadas propostas para seu aprimoramento.

\section{AGRADECIMENTOS}

O primeiro autor agradece a Fundação Cearense de Apoio ao Desenvolvimento Científico e Tecnológico (FUNCAP) pela concessão da Bolsa de Formação Acadêmica, Modalidade Mestrado, junto ao Programa de PósGraduação em Geografia da Universidade Federal do Ceará (PPGG - UFC).

\section{REFERÊNCIAS BIBLIOGRÁFICAS}

AB'SÁBER, Aziz Nacib. Províncias geológicas e domínios morfoclimáticos do Brasil. Geomorfologia. São Paulo, IGEOG. USP. v. 20,1970,

AB'SABER, Aziz Nacib. O domínio morfoclimático semi-árido das caatingas brasileiras. Geomorfologia, São Paulo, n. 43, p. 1-39, 1974.

AYOADE, J. O. A re-examination of Thornthwaite's moisture index and climatic classification. Quartely Meteorological Magazine (Lagos), v. 3, no 4, p. 190-204, 1972.

AYOADE, J. O. Introdução à climatologia para os trópicos. 15. ed. Rio de Janeiro: Bertrand Brasil, 2011. 332 p.

BASTOS, Frederico de Holanda et. al. Aspectos geoambientais e contribuições para estratégias de planejamento ambiental da serra de Baturité/CE. Revista da Associação Nacional de Pós-graduação e Pesquisa em Geografia (Anpege). v. 13, n. 21, p.164-198, ago. 2017.

BÉTARD, François et. al. Caracterização morfopedológica de uma serra úmida no semi-árido do Nordeste brasileiro: o caso do maciço de Baturité-CE. Mercator: Revista de Geografia da UFC, Fortaleza, ano 06, n. 12, p.107-126, 2007.

BRANDÃO, R.L. Geodiversidade do Estado do Ceará. Fortaleza: CPRM, 2014, 214p. 
CÂNDIDO, Daniel Henrique; NUNES, Lucí Hidalgo. Influência da orografia na precipitação da área entre o vale do rio Tietê e a serra da Mantiqueira. Geousp: Espaço e Tempo, São Paulo, n. 24, p. 8-27, 2008.

CONTI, José Bueno. A questão climática do Nordeste brasileiro e os processos de desertificação. Revista Brasileira de Climatologia, Curitiba, v. 1, n. 1, p.7-14, dez. 2005.

COSTA, Gessivaldo. CELINA - Estimativa de Temperaturas Para o Estado do Ceará. Versão 1.0. UFC, 2007

FERREIRA, A.G.; MELLO, N.G.S. Principais sistemas atmosféricos atuantes sobre a região Nordeste do Brasil e a influência dos oceanos pacífico e Atlântico no clima da região. Revista Brasileira de Climatologia, Ano 1, dez. 2005.

FUNCEME. Fundação Cearense de Meteorologia e Recursos Hídricos. Base de dados pluviométricos. Fortaleza: FUNCEME, 2019. Disponível em (http://www.funceme.br) Acesso em 25 de junho de 2019.

KRISHNAN, A. Agroclimatic classification methods and their application to India. In: VIRMANI, S. M.; SIVAKUMAR, M. V. K.. Climatic Classification: A Consultants' Meeting. Patancheru: Icrisat (International Crops Research Institute For The Semi-arid Tropics), 1980. p. 59-88.

NIMER, Edmon; BRANDÃO, Ana Maria P. M. Balanço hídrico anual a partir de valores normais e tipologia climática. Revista Brasileira de Geografia, Rio de Janeiro, v. 1, n. 1, p.373-416, jul. 1985.

NIMER, E. Climatologia do Brasil. Rio de Janeiro, IBGE, 1989

PEREIRA, Antonio Roberto. Simplificando o balanço hídrico de ThornthwaiteMatter. Bragantia, Campinas, v. 64, n. 2, p.311-313, 2005.

REDDY, S. Jeevananda. Climatic classification: the semi-arid tropics and its environment - A review. Pesquisa Agropecuária Brasileira, Brasília, v. 8, n. 18, p.823-847, ago. 1983.

ROLIM, G.S.; SENTELHAS, P.C.; BARBIERI, V. Planilhas no ambiente EXCEL para os cálculos de balanços hídricos: normal, sequencial, de cultura e de produtividade real e potencial. Revista Brasileira de Agrometeorologia, Santa Maria, v.6, p.133-137, 1998

ROLIM, G. S. et al. Climatic classification of Köppen and Thornthwaite systems and their applicability in the determination of agroclimatic zonning for the state of São Paulo, Brazil. Bragantia. v. 66, p.711-720, 2007.

SOUZA, Marcos José Nogueira de. Contribuição ao estudo das unidades morfoestruturais do Estado do Ceará. Revista de Geologia. Fortaleza: (n० 1) Edições Universidade Federal do Ceará, p 73-91, 1988.

SOUZA, Marcos José Nogueira de; OLIVEIRA, Vládia Pinto Vidal de. Os enclaves úmidos e sub-úmidos do semiárido do Nordeste brasileiro. Mercator: Revista de Geografia da UFC, Fortaleza, ano 05, n. 09, p.85-101, 2006.

THORNTHWAITE, C. W. An approach towards a rational classification of climate. Geographical Review, n. 38, p. 55-94, 1948.

THORNTHWAITE, C. W. \& MATHER. J. R. The Water Balance. Publications in Climatology, VIII (1), Centerton, N. Jersey, 1955 
THORNTHWAITE, C. W \& MATHER. J. R. Instructions and Tables for computing Potential Evapotranspiration and the Water Balance. Publications in Climatology. X (3), Centerton, N. Jersey, 1957.

VAREJÃO-SILVA, M. A. Meteorologia e climatologia. Brasília: INMET, 2001. 515p.

ZANELLA, Maria Elisa. Considerações sobre o clima e os recursos hídricos do semiárido nordestino. Caderno Prudentino de Geografia, Presidente Prudente, Volume Especial, n. 36, p.126-142, 2014. 